\title{
An Extended TODIM Method for Group Decision Making with the Interval Intuitionistic Fuzzy Sets
}

\author{
Yanwei Li, Yuqing Shan, and Peide Liu \\ College of Economics and Management, Civil Aviation University of China, Tianjin 300300, China \\ Correspondence should be addressed to Yuqing Shan; shanyuqing27@163.com
}

Received 3 December 2014; Revised 6 March 2015; Accepted 24 March 2015

Academic Editor: Elena Benvenuti

Copyright (C) 2015 Yanwei Li et al. This is an open access article distributed under the Creative Commons Attribution License, which permits unrestricted use, distribution, and reproduction in any medium, provided the original work is properly cited.

\begin{abstract}
For a multiple-attribute group decision-making problem with interval intuitionistic fuzzy sets, a method based on extended TODIM is proposed. First, the concepts of interval intuitionistic fuzzy set and its algorithms are defined, and then the entropy method to determine the weights is put forward. Then, based on the Hamming distance and the Euclidean distance of the interval intuitionistic fuzzy set, both of which have been defined, function mapping is given for the attribute. Finally, to solve multiple-attribute group decision-making problems using interval intuitionistic fuzzy sets, a method based on extended TODIM is put forward, and a case that deals with the site selection of airport terminals is given to prove the method.
\end{abstract}

\section{Introduction}

Zadeh [1] put forward the concept of fuzzy sets in 1965; shortly afterward, the theory of fuzzy sets gradually developed. In 1986, Atanassov [2] proposed the theory of intuitionistic fuzzy set (IFS). However, the common fuzzy set can be seen as the special form of IFS. In real life, an accurate definition for the specific membership and the specific nonmembership degree of IFS is relatively difficult [3]. In 1989, Atanassov and Gargov [4] extended the IFS into the interval intuitionistic fuzzy set (IIFS). In the following years, the properties of the IIFSs were further expanded, the changes mainly included related algorithms, the correlation and decomposition theorem, topological properties, correlation coefficient, and the relationship between other fuzzy sets [5-9]. $\mathrm{Xu}[10]$ also put forward several kinds of weighted averaging operators for the IIFSs in 2007. Also, there are some applications and extensions for these operators [11-13].

Multiple-attribute decision making (MADM) belongs to multicriteria decision making (MCDM), which has characteristics of discrete types and limited alternatives. The process of decision making is to gather the opinions of all the decision makers for several alternatives. MADM means that there is not only one attribute, and how to integrate the attributes of various alternatives is very important. Therefore, many researchers have devoted themselves to the study of MADM, and rich achievements have been obtained. Specific methods have been used to solve the problems of multiple-attribute decision making, such as the method of choice [14, 15], the ordering method of compromise [16], the method of grey correlation analysis $[17,18]$, and the TOPSIS method $[19,20]$. There are also many other methods [21-25], and multipleattribute group decision making has a wide array of theory and practice basis $[26,27]$.

Park et al. [28] pointed out that problems in which the attribute weights were unknown and interval intuitionistic fuzzy decision was being applied were difficult. At present, general methods used to solve the problem of multipleattribute decision making with IFS are based on the determination attribute weights $[29,30]$. In the recent years, under the condition in which attribute weights are determined, studies have made great progress solving the problem of multiattribute group decision making using interval number information. For example, Bryson and Mobolurin [31] proposed a method of linear programming which was based on the deviation degree. $\mathrm{Xu}$ [32] presented the method of relative membership degree. Su et al. [33] put forward an extended VIKOR method for dynamic multiattribute decision making using interval numbers. And Wang et al. did some research that included the condition of uncertainty $[34,35]$. 
However, the methods used to solve the problems that concerned MADM with IIFS have been extended. Some methods involving MADM with IIFS can be understood as follows. $\mathrm{Hu}$ and $\mathrm{Xu}$ [36] proposed the TOPSIS method. Qi et al. [37] gave an approach to include automatic convergence. A dynamic multiple-attribute grey incidence decisionmaking method was put forward by Liu et al. [38]. Chen [39] developed a qualities-based method for handling problems, and he applied a confidence interval to the membership degree and the nonmembership degree.

Gomes and Lima [40, 41] proposed the TODIM (an acronym in Portuguese of interactive and multicriteria decision making) method, which was based on prospect theory [42]. The TODIM method is used to establish the expected function, which measures the degree to which one alternative is superior to others by calculating accurate number information. The TODIM method was successfully applied to the MADM for the first time by Gomes and Rangel [43], and it has proved to be an effective method for dealing with MADM. Krohling and De Souza [44] applied the TODIM method to the attribute values, which are specifically expressed as the IIFS. In addition, the TODIM method has provided a great help in solving real problems. TODIM methods were expanded by Fan et al. [45]. In the future, TODIM methods can deal with three types of information, including the real number, the interval number, and the triangular fuzzy number [46].

The traditional TODIM method mainly handles real numbers where the weights are known and only one decision maker appears in the MADM problems. The IIFS is used to express the opinions of every expert for every alternative, because its description is more accurate than other mathematical linguistics. In this paper, multiple-attribute group decision making is studied by using the extended TODIM method, which is represented by IIFSs. The TODIM method aims to optimize the ranking of alternatives. In addition, the entropy method for the determination of weights is put forward. We can derive the expert weights according to the score function, and the attribute weights can be derived by the idea of maximum entropy.

The structure of this paper is arranged as follows. In Section 2, the definition and algorithms of the IIFS are proposed. In Section 3, the group decision-making matrix for the IIFSs is described. In Section 4, the method to determine the weights is given in detail. In Section 5, the extended TODIM method for interval intuitionistic fuzzy information is put forward, and the steps of how to solve the problem of multiple-attribute group decision making are listed one by one. In the end, a case concerning the site selection of airport terminals is shown to demonstrate the proposed method and its results.

\section{Definitions of IIFSs}

Because the concept of IIFS is derived from intuitionistic fuzzy sets, we first define IFS. On the basis of that, IIFS will be defined. The basic algorithms of the IIFS are given, as well as a description of its operators.
Definition 1 (intuitionistic fuzzy set (IFS) [2]). Let $A$ be an IFS; it can be represented as follows:

$$
A=\langle x, u(x), v(x) \mid x \in R\rangle .
$$

In this definition, $u(x)$ represents the membership of the element $x$ in the IFS, and $v(x)$ represents the nonmembership degree of the element $x$ in the IFS. Let $\pi(x)$ represent the hesitancy degree of $A$; that is, $\pi(x)=1-u(x)-v(x)$.

This expression should satisfy the following conditions:

(1) $R$ is a nonempty set;

(2) $0 \leq u(x) \leq 1,0 \leq v(x) \leq 1$, and $0 \leq \pi(x) \leq 1$.

Definition 2 (interval intuitionistic fuzzy set (IIFS) [4]). Let $\widetilde{H}$ be an IIFS; it can be represented as follows:

$$
\widetilde{H}=\left\langle\left[u^{\alpha}(x), u^{\beta}(x)\right],\left[v^{\alpha}(x), v^{\beta}(x)\right] \mid x \in R\right\rangle .
$$

In this definition, $u^{\alpha}(x)$ represents the lower limit of the membership degree of the element $x ; u^{\beta}(x)$ represents the upper limit of the membership degree of the element $x ; v^{\alpha}(x)$ represents the lower limit of the nonmembership degree of the element $x$; and $v^{\beta}(x)$ represents the upper limit of the nonmembership degree of the element $x$. In addition, let $\tilde{\pi}(x)$ be the hesitancy degree of $\widetilde{H}$; that is, $\widetilde{\pi}(x)=(\widetilde{\mu}(x) \cup \widetilde{v}(x))^{c}$. This is equal to $\left[1-u^{\beta}(x)-v^{\beta}(x), 1-u^{\alpha}(x)-v^{\alpha}(x)\right]$.

This expression should satisfy the following conditions:

(1) $R$ is a nonempty set;

(2) $u^{\alpha}(x) \in[0,1], u^{\beta}(x) \in[0,1]$, and $v^{\alpha}(x) \in[0,1]$, $v^{\beta}(x) \in[0,1]$

(3) $\left[u^{\alpha}(x), u^{\beta}(x)\right] \subset[0,1],\left[v^{\alpha}(x), v^{\beta}(x)\right] \subset[0,1]$, and $0 \leq u^{\alpha}(x)+v^{\alpha}(x) \leq 1$

Definition 3 (the basic algorithms of IIFS [4]). Given the following assumptions, let $\widetilde{h}_{1}$ and $\widetilde{h}_{2}$ be two interval intuitionistic fuzzy numbers:

$$
\begin{aligned}
& \tilde{h}_{1}=\left(\left[u_{1}^{\alpha}(x), u_{1}^{\beta}(x)\right],\left[v_{1}^{\alpha}(x), v_{1}^{\beta}(x)\right]\right), \\
& \tilde{h}_{2}=\left(\left[u_{2}^{\alpha}(x), u_{2}^{\beta}(x)\right],\left[v_{2}^{\alpha}(x), v_{2}^{\beta}(x)\right]\right) .
\end{aligned}
$$

Then we have these basic algorithms:

$$
\begin{gathered}
\tilde{h}_{1}+\widetilde{h}_{2}=\left(\left[u_{1}^{\alpha}(x)+u_{2}^{\alpha}(x)-u_{1}^{\alpha}(x) * u_{2}^{\alpha}(x),\right.\right. \\
\left.u_{1}^{\beta}(x)+u_{2}^{\beta}(x)-u_{1}^{\beta}(x) * u_{2}^{\beta}(x)\right], \\
\left.\left[v_{1}^{\alpha}(x) * v_{2}^{\alpha}(x), v_{1}^{\beta}(x) * v_{2}^{\beta}(x)\right]\right), \\
\widetilde{h}_{1} * \widetilde{h}_{2}=\left(\left[u_{1}^{\alpha}(x) * u_{2}^{\alpha}(x), u_{1}^{\beta}(x) * u_{2}^{\beta}(x)\right],\right. \\
{\left[v_{1}^{\alpha}(x)+v_{2}^{\alpha}(x)-v_{1}^{\alpha}(x) * v_{2}^{\alpha}(x),\right.} \\
\left.\left.v_{1}^{\beta}(x)+v_{2}^{\beta}(x)-v_{1}^{\beta}(x) * v_{2}^{\beta}(x)\right]\right), \\
\lambda \widetilde{h}_{1}=\left(\left[1-\left(1-u_{1}^{\alpha}(x)\right)^{\lambda}, 1-\left(1-u_{1}^{\beta}(x)\right)^{\lambda}\right],\right. \\
\left.\left[v_{1}^{\alpha}(x)^{\lambda}, v_{1}^{\beta}(x)^{\lambda}\right]\right) .
\end{gathered}
$$


Definition 4 (IIFWA [10]). The interval intuitionistic fuzzy weighted averaging (IIFWA) operator is a kind of aggregating operator, which evolved from the intuitionistic fuzzy weighted averaging (IFWA) operator. This operator has been proven, and its specific form is

$$
\begin{aligned}
& \operatorname{IIFWA}_{w}\left(h_{1}, h_{2}, \ldots, h_{n}\right) \\
&=\left(\left[1-\prod_{i=1}^{n}\left(1-u_{i}^{\alpha}(x)\right)^{w_{i}}, 1-\prod_{i=1}^{n}\left(1-u_{i}^{\beta}(x)\right)^{w_{i}}\right],\right. \\
& {\left.\left[\prod_{i=1}^{n} v_{i}^{\alpha}(x)^{w_{i}}, \prod_{i=1}^{n} v_{i}^{\beta}(x)^{w_{i}}\right]\right), }
\end{aligned}
$$

where $w_{i} \geq 0, i \in 0,1,2 \ldots, n$, and $\sum_{i=1}^{n} w_{i}=1$, and $w_{i}$ is the weight of $h_{i}$.

Definition 5 (the distances of IIFSs). Alternatives will be evaluated according to the distance of IIFS. Based on the Hamming distance and the Euclidean distance of IFS, we can extend to the normalized Hamming distance and the normalized Euclidean distance of IIFS. Its specific form is as follows.

Definition 5.1. The normalized Hamming distance of interval intuitionistic fuzzy is as follows:

$$
\begin{aligned}
d^{H}\left(\widetilde{h}_{1}, \widetilde{h}_{2}\right)=\frac{1}{4}( & \left|u_{1}^{\alpha}(x)-u_{2}^{\alpha}(x)\right|+\left|u_{1}^{\beta}(x)-u_{2}^{\beta}(x)\right| \\
& \left.+\left|v_{1}^{\alpha}(x)-v_{2}^{\alpha}(x)\right|+\left|v_{1}^{\beta}(x)-v_{2}^{\beta}(x)\right|\right) .
\end{aligned}
$$

Definition 5.2. The normalized Euclidean distance of interval intuitionistic fuzzy is as follows:

$$
\begin{aligned}
& d^{E}\left(\widetilde{h}_{1}, \widetilde{h}_{2}\right) \\
& =\frac{1}{2}\left(\left(u_{1}^{\alpha}(x)-u_{2}^{\alpha}(x)\right)^{2}+\left(u_{1}^{\beta}(x)-u_{2}^{\beta}(x)\right)^{2}\right. \\
& \left.\quad+\left(v_{1}^{\alpha}(x)-v_{1}^{\alpha}(x)\right)^{2}+\left(v_{1}^{\beta}(x)-v_{2}^{\beta}(x)\right)^{2}\right)^{1 / 2} .
\end{aligned}
$$

Definition 6 (the score function of IIFS [10]). Let $\widetilde{h}$ be an interval intuitionistic fuzzy number: $\widetilde{h}=\left(\left[u^{\alpha}(x), u^{\beta}(x)\right]\right.$, $\left.\left[v^{\alpha}(x), v^{\beta}(x)\right]\right)$, and let $S(\widetilde{h})$ be the score function of $\widetilde{h}$ :

$$
S(\widetilde{h})=\frac{1}{2}\left(\left(u^{\alpha}(x)+u^{\beta}(x)\right)-\left(v^{\alpha}(x)+v^{\beta}(x)\right)\right) .
$$

When $S\left(\widetilde{h}_{1}\right)<S\left(\widetilde{h}_{2}\right)$, there is $\widetilde{h}_{1}<\widetilde{h}_{2}$.

\section{Description of the Group Decision-Making Matrix with IIFSs Information}

For a multiple-attribute group decision-making problem, we suppose that there is an alternative set $A$; its form is $A=$ $(1,2,3, \ldots, n)$, and the attributes of the alternative set can be expressed as $C=(1,2,3, \ldots, m)$. Let $D$ be the decisionmaker set; that is, $D=(1,2,3, \ldots, h)$. The decision-maker $k$ evaluates the attributes $j$ of alternative $i$ by the form of IIFS. This process of assignment can be expressed as a matrix of $\vec{P}_{i j}^{k}(n \times m)=\left(\left[u_{i j k}^{\alpha}(x), u_{i j k}^{\beta}(x)\right],\left[v_{i j k}^{\alpha}(x), v_{i j k}^{\beta}(x)\right]\right)$, and the evaluation matrix of all decision makers can be expressed as $\left(\vec{P}_{i j}^{1}, \vec{P}_{i j}^{2}, \ldots, \vec{P}_{i j}^{h}\right)^{T}$.

Definition 7 (the aggregating of the experts matrix). The IIFWA operator is adopted to aggregate the expert matrix. In this case, we suppose that the weight of expert $q_{i}$ is known. After a series of calculations, we will derive the aggregation of the experts matrix as $\vec{R}(m \times n)$; the element of $\vec{R}(m \times n)$ is $r_{i j}$, which means that experts evaluate every attribute $j$ of every alternative $i$. That is to say, when all of the experts' evaluations of all of the alternatives are put together, they equal one expert's evaluation of all of the alternatives. So, we consider this matrix an overall evaluation matrix:

$$
\begin{aligned}
r_{i j}=( & {\left[1-\prod_{k=1}^{h}\left(1-u_{i j k}^{\alpha}(x)\right)^{q_{k}},\right.} \\
& \left.1-\prod_{k=1}^{h}\left(1-u_{i j k}^{\beta}(x)\right)^{q_{k}}\right], \\
& {\left.\left[\prod_{k=1}^{h} v_{i j k}^{\alpha}(x)^{q_{k}}, \prod_{k=1}^{h} v_{i j k}^{\beta}(x)^{q_{k}}\right]\right), }
\end{aligned}
$$

where $q_{k} \geq 0, i \in 0,1,2, \ldots, h$, and $\sum_{k=1}^{h} q_{k}=1$.

\section{Entropy Weight Method for Group Decision Making with IIFS}

The concept of entropy is derived from thermodynamics. C. E. Shannon has recently applied it to information theory. The basic principle is that entropy can be used as a measure of the useful information that the data provides. The entropy weight method has been widely used in the decision-making process. In this paper, the entropy coefficient method is applied to determine the weights of experts and attributes in group decision making using IIFS.

\subsection{Entropy Weight Method for Determination of Expert Weights}

Definition 8 (the entropy of expert). Let $E_{k}$ be the entropy of expert $k$ :

$$
E_{k}=-\frac{1}{\ln n} \sum_{i=1}^{i=n}\left(\frac{s_{i k}}{\sum_{i=1}^{n} s_{i k}} * \ln \left|\frac{s_{i k}}{\sum_{i=1}^{n} s_{i k}}\right|\right),
$$

where $s_{i k}$ can be calculated by formula (12), and its form is as follows:

$$
s_{i k}=\frac{1}{2} \sum_{j=1}^{m}\left(\left(u_{i j k}^{\alpha}(x)+u_{i j k}^{\beta}(x)\right)-\left(v_{i j k}^{\alpha}(x)+v_{i j k}^{\beta}(x)\right)\right) .
$$


Formula (11) is based on the score function, which is proposed by $\mathrm{Xu}$ [10]. It is used to calculate the overall evaluating values of expert $k$ to the alternative $i$.

Definition 9 (the expert weights). Using the properties of entropy, we find that if the degree of disorder in a system is high, the entropy value will correspondingly be larger. In group decision making, if experts have similar opinions about different alternatives, the entropy value will be larger. That is, the greater the entropy value of expert $E_{k}$ is, the smaller the differences the results will show. Let $q_{k}$ be the entropy weight of expert $k$; its form will be as follows:

$$
q_{k}=\frac{1-E_{k}}{h-\sum_{k=1}^{h}\left(E_{k}\right)},
$$

where $0 \leq q_{k} \leq 1$ and $\sum_{k=1}^{h} q_{k}=1$.

\subsection{Entropy Weight Method for Determination of Attribute Weights}

Definition 10 (the entropy of attributes). Let $e_{j}$ be the entropy of attribute $j$ :

$$
e_{j}=-\frac{1}{\ln n} \sum_{i=1}^{n}\left(\frac{h_{i j}}{\sum_{j=1}^{m} h_{i j}} * \ln \left(\frac{h_{i j}}{\sum_{j=1}^{m} h_{i j}}\right)\right),
$$

where $h_{j}$ can be calculated by formula (16), and its form is as follows [37]:

$$
\begin{gathered}
h_{i j}=\left(1-d\left(\left(\left[\widetilde{u}_{i j}^{\alpha}(x), \widetilde{u}_{i j}^{\beta}(x)\right],\left[\widetilde{v}_{i j}^{\alpha}(x), \widetilde{v}_{i j}^{\beta}(x)\right]\right),\right.\right. \\
([0.5,0.5],[0.5,0.5]))) .
\end{gathered}
$$

Formula (14) has to satisfy the following conditions:

(1) the relative importance of evaluation attributes and alternatives is independent;

(2)

$$
\begin{aligned}
& d\left(\tilde{r}_{i j},([0.5,0.5],[0.5,0.5])\right) \\
& =\frac{1}{2}\left(\left(u_{i j}^{\alpha}(x)-0.5\right)^{2}+\left(u_{i j}^{\beta}(x)-0.5\right)^{2}\right. \\
& \left.\quad+\left(v_{i j}^{\alpha}(x)-0.5\right)^{2}+\left(v_{i j}^{\beta}(x)-0.5\right)^{2}\right)^{1 / 2}
\end{aligned}
$$

(3) if there is $d(\widetilde{\alpha},([0.5,0.5],[0.5,0.5])) \geq d(\widetilde{\beta},([0.5,0.5]$, $[0.5,0.5]))$ for any two IIFSs, then there will be $h(\widetilde{\alpha}) \leq$ $h(\widetilde{\beta})$.

Formula (14) is based on the Euclidean distance of IIFS. The interval intuitionistic fuzzy number $([0.5,0.5],[0.5,0.5])$ has no hesitancy degree, but its entropy attains the maximum value. That is to say, the positive and negative evidence of this number are accounted equally, and it is impossible to use fuzzy information to describe or make a reasonable judgment.
Definition 11 (the attribute weight). According to the theory of entropy, when the entropy of attribute $j$ is greater than the value of other attributes, the value of attribute $j$ between every alternative and the optimal strategy will have a smaller difference. In order to facilitate a comprehensive evaluation, the weight of attribute $j$ can be determined by $e_{j}$. Let $w_{j}$ be the weight of attribute $j$; it is formed as follows:

$$
w_{j}=\frac{1-e_{j}}{m-\sum_{j=1}^{m}\left(e_{j}\right)},
$$

where $0 \leq w_{j} \leq 1$ and $\sum_{j=1}^{m} w_{j}=1$.

\section{The Extended TODIM Method for Group Decision Making with IIFS}

Based on the above discussion, which included the concept of IIFSs, as well as its basic algorithms and the gathering method of the interval intuitionistic fuzzy matrix, a new method of processing multiattribute group decision making is given, which is called the extended TODIM method. The traditional TODIM method measures the comprehensive degree of an alternative better than others and is extended in this paper to handle IIFS. Assuming the conditions that (a) weights of the experts and attributes are unknown and (b) there is more than one decision maker, we outline the steps of how to use the TODIM method in the next segment.

Step 1. There are $K$ experts to evaluate every attribute of $n$ alternatives. When evaluating alternatives, IIFSs are used to express the evaluating values. After that, an assessment matrix $\vec{P}_{i j}^{k}$ of every $k$ th expert will be derived; each row represents an attribute, and the columns represent alternatives. All of the assessment matrices can be expressed as $\left(\vec{P}_{i j}^{1}, \vec{P}_{i j}^{2}, \ldots, \vec{P}_{i j}^{h}\right)^{T}$.

Step 2. Calculate the expert weights. The weight measure $q_{k}$ can be determined according to formulas (10) through (12).

Step 3. Aggregate all of the assessment matrices $\vec{P}_{i j}^{k}$. On the premise that the obtained weight values of every expert $q_{k}$ can be expressed by $(i=1,2, \ldots, h)$, formula (9) is applied to assemble the advice of $h$ experts, and the aggregating matrix $\vec{R}(m \times n)$ can be derived.

Step 4. Calculate the attribute weights. On the basis of Step 3 , the weight measure $w_{j}$ can be determined according to formulas (13) through (16).

Step 5. According to the Hamming distance (Definition 5.1) and the Euclidean distance (Definition 5.2) of IIFSs, the distance between every element in the aggregating matrix and the interval intuitionistic fuzzy number $([0,0],[1,1])$ can be calculated, respectively, and matrix $Y$ can be obtained after the distance is gathered into expression (18), which is shown below. Let $y_{i j}$ be the element of matrix $Y$, where $\tilde{r}_{i j}$ represents the element of the aggregating matrix $\vec{R}(m \times n)$ :

$$
y_{i j}=d\left(\widetilde{r}_{i j},([0,0],[1,1])\right) \text {. }
$$


The interval intuitionistic fuzzy number $([0,0],[1,1])$ is the minimum, so we can define it as the negative ideal point. When the distance between an alternative and this point is larger, the result will be more accurate.

Step 6. When matrix $Y$ that has been derived is brought into expression (18), matrix $I$ will be derived. The function $I\left(A_{i}, A_{j}\right)$ is used to represent the degree to which alternative $i$ is better than alternative $j$ and is the sum of the subfunction $\Phi_{c}\left(A_{i}, A_{j}\right)$ where $c$ applies from 1 to $m$. Subfunction $\Phi_{c}\left(A_{i}, A_{j}\right)$ indicates the degree to which alternative $i$ is better than alternative $j$ when a particular attribute $c$ is given.

In expression (18), there is a constant parameter $\pi$, which is used to represent the sensitive coefficient of risk aversion. When the parameter $\pi$ has different values, the values of subfunction $\Phi_{c}\left(A_{i}, A_{j}\right)$ will change correspondingly:

$$
\Phi_{c}\left(A_{i}, A_{j}\right)= \begin{cases}\sqrt{\frac{w_{c}\left(y_{i c}-y_{j c}\right)}{\sum_{c=1}^{m} w_{c}}} & y_{i c}>y_{j c} \\ -\frac{1}{\pi} \sqrt{\frac{\left(\sum_{c=1}^{m} w_{c}\right)\left(y_{j c}-y_{i c}\right)}{w_{c}}} & y_{i c}<y_{j c} \\ 0 & y_{i c}=y_{j c}\end{cases}
$$

$$
I\left(A_{i}, A_{j}\right)=\sum_{c=1}^{m} \Phi\left(A_{i}, A_{j}\right) \quad i, j \in A .
$$

Step 7. According to expression (20), the overall appraisal values of alternatives can be worked out, and these values should be sorted. If the value $\xi\left(A_{i}\right)$ is larger than other values, then alternative $i$ will be more optimal. Function $\xi\left(A_{i}\right)$ will be obtained by matrix $I$, and $\xi\left(A_{i}\right)$ represents the degree of priority by which alternative $i$ is preferred over the others. Therefore, these alternatives can be sorted according to the results of function $\xi\left(A_{i}\right)$. That is to say, if the result of function $\xi\left(A_{i}\right)$ is larger, this alternative will be more optimal than others:

$$
\begin{aligned}
& \xi\left(A_{i}\right) \\
& \quad=\frac{\sum_{j=1}^{n} I\left(A_{i}, A_{j}\right)-\min _{1 \leq i \leq n} \sum_{j=1}^{n} I\left(A_{i}, A_{j}\right)}{\max _{1 \leq i \leq n} \sum_{j=1}^{n} I\left(A_{i}, A_{j}\right)-\min _{1 \leq i \leq n} \sum_{j=1}^{n} I\left(A_{i}, A_{j}\right)} .
\end{aligned}
$$

Step 8. Rank the values of function $\xi\left(A_{i}\right)$ and analyze the results.

\section{Analysis of Examples: The Site Selection of Airport Terminals}

An airfield plans to construct different airport terminals in surrounding cities. After preliminary screening, several cities remain for further analysis and research. First, a comprehensive evaluation index system should be established, starting from the following three aspects: number of potential customers, degree of traffic connections, and the existing competitive capacity.

The number of potential customers can refer not only to the volume of airline passenger transportation and the rate of growth in recent years, but also to the local economic conditions, such as local GDP, industrial patterns, and other enterprises. The degree of traffic connections mainly takes other modes of transport into account, considers whether the others are convenient and fast and have a high coverage rate throughout the city, and also considers the convenience degree of each traffic connection from the city to the surrounding areas. The existing competitive capacity mainly means the competitive pressures coming from high-speed rail and airport terminals of other airfields, the degree of local government supporting the air transportation industry, and the advantages of relevant policies.

Suppose there are five alternative cities $A_{i}(i=1,2$, $3,4,5)$. Three experts $D_{k}(k=1,2,3)$ in the field of aviation are invited to evaluate the five cities using IIFSs. According to the above evaluation index system about remote airport terminals, a similar description of attributes can be made as follows: attribute $C_{1}$ signifies the amount of potential customers, attribute $C_{2}$ signifies the degree of traffic connections, and attribute $C_{3}$ signifies the existing competitive capacity. For the above three indices, IIFSs are adopted to express the evaluated values. When assigning the evaluating values, we assume that the attribute dimensions have been eliminated. Thus, this data can be seen as normalized.

Specific steps are as follows.

Step 1. Determination of basic data: the three matrices below represent the three experts' evaluation of the five cities for every attribute:

$$
P^{1}=\left|\begin{array}{cccc}
C_{1} & C_{2} & C_{3} \\
A_{1} & ([0.60,0.79],[0.10,0.15]) & ([0.40,0.50],[0.30,0.40]) & ([0.50,0.60],[0.30,0.35]) \\
A_{2} & ([0.70,0.75],[0.10,0.20]) & ([0.60,0.65],[0.20,0.30]) & ([0.70,0.80],[0.05,0.10]) \\
A_{3} & ([0.50,0.60],[0.20,0.25]) & ([0.70,0.75],[0.10,0.20]) & ([0.30,0.40],[0.30,0.40]) \\
A_{4} & ([0.30,0.35],[0.20,0.25]) & ([0.50,0.60],[0.10,0.15]) & ([0.60,0.70],[0.20,0.25]) \\
A_{5} & ([0.70,0.75],[0.15,0.20]) & ([0.30,0.40],[0.20,0.25]) & ([0.65,0.70],[0.20,0.30])
\end{array}\right|,
$$




$$
\begin{aligned}
& P^{2}=\left|\begin{array}{cccc}
C_{1} & C_{2} & C_{3} \\
A_{1} & ([0.50,0.65],[0.10,0.20]) & ([0.30,0.40],[0.20,0.30]) & ([0.40,0.50],[0.35,0.45]) \\
A_{2} & ([0.80,0.90],[0.05,0.10]) & ([0.50,0.60],[0.20,0.30]) & ([0.60,0.70],[0.20,0.30]) \\
A_{3} & ([0.60,0.70],[0.20,0.25]) & ([0.50,0.60],[0.20,0.25]) & ([0.30,0.40],[0.20,030]) \\
A_{4} & ([0.50,0.60],[0.20,0.30]) & ([0.70,0.80],[0.10,0.15]) & ([0.70,0.75],[0.20,0.25]) \\
A_{5} & ([0.70,0.80],[0.10,0.20]) & ([0.20,0.30],[0.20,0.25]) & ([0.50,0.55],[0.20,0.25])
\end{array}\right|, \\
& P^{3}=\left|\begin{array}{cccc}
C_{1} & C_{2} & C_{3} \\
A_{1} & ([0.40,0.50],[0.20,0.25]) & ([0.50,0.60],[0.20,0.25]) & ([0.30,0.40],[0.50,0.60]) \\
A_{2} & ([0.60,0.65],[0.20,0.30]) & ([0.30,0.35],[0.10,0.20]) & ([0.60,0.65],[0.30,0.35]) \\
A_{3} & ([0.40,0.45],[0.10,0.15]) & ([0.80,0.90],[0.00,0.10]) & ([0.40,0.45],[0.20,030]) \\
A_{4} & ([0.20,0.30],[0.40,0.50]) & ([0.60,0.65],[0.20,0.25]) & ([0.55,0.15],[0.40,0.50]) \\
A_{5} & ([0.90,1.00],[0.30,0.40]) & ([0.20,0.30],[0.40,0.45]) & ([0.60,0.70],[0.20,0.25])
\end{array}\right| .
\end{aligned}
$$

Step 2. Calculating the values of expert weight: according to formulas (10) through (12), the results are shown in Table 1 and the following:

$$
E_{k}=\left|\begin{array}{ccc}
D_{1} & D_{2} & D_{3} \\
0.981 & 0.965 & 0.883
\end{array}\right| .
$$

Finally, the expert weights can be worked out and the results are

$$
q_{k}=\left|\begin{array}{ccc}
D_{1} & D_{2} & D_{3} \\
0.114 & 0.203 & 0.683
\end{array}\right|
$$

Step 3. The above three matrices of the five cities can apply Definition 6, and, in this manner, they can be integrated into a matrix. The results of the matrix are shown in Table 2.

Step 4. Calculate the values of the attribute weights. On the basis of Step 3, the weight measure $w_{j}$ can be determined according to formulas (13) through (16), and the results are as shown in Table 3 and the following:

$$
e_{j}=\left|\begin{array}{ccc}
C_{1} & C_{2} & C_{3} \\
0.9978 & 0.9974 & 0.9989
\end{array}\right| \text {. }
$$

Finally, the attribute weights can be worked out and the results are as follows:

$$
W_{j}=\left|\begin{array}{ccc}
C_{1} & C_{2} & C_{3} \\
0.371 & 0.435 & 0.194
\end{array}\right|
$$

Step 5. Calculate the distance between the IIFSs in matrix $R$ with $([0,0],[1,1])$.

(1) Calculating by the Hamming distance, the results are as follows:

$$
Y^{H}=\left|\begin{array}{cccc} 
& C_{1} & C_{2} & C_{3} \\
A_{1} & 0.656 & 0.631 & 0.456 \\
A_{2} & 0.758 & 0.621 & 0.694 \\
A_{3} & 0.672 & 0.868 & 0.571 \\
A_{4} & 0.482 & 0.731 & 0.508 \\
A_{5} & 0.829 & 0.457 & 0.702
\end{array}\right| .
$$

(2) Calculating by the Euclidean distance, the results are as follows:

$$
Y^{E}=\left|\begin{array}{cccc} 
& C_{1} & C_{2} & C_{3} \\
A_{1} & 0.675 & 0.645 & 0.462 \\
A_{2} & 0.762 & 0.655 & 0.696 \\
A_{3} & 0.696 & 0.872 & 0.597 \\
A_{4} & 0.507 & 0.736 & 0.526 \\
A_{5} & 0.837 & 0.499 & 0.706
\end{array}\right| .
$$

Step 6. The degree by which a given alternative is superior to all of the others can be calculated using the extended TODIM method. First, work out the values of function $\Phi_{c}\left(A_{i}, A_{j}\right)$, and then the values of function $I$ may be calculated. The value of parameter $\pi$ is given as 0.9 , because of the principle that 
TABLE 1

\begin{tabular}{lccc}
\hline$s_{i k}$ & $D_{1}$ & $D_{2}$ & $D_{3}$ \\
\hline$A_{1}$ & 0.850 & 0.575 & 0.350 \\
$A_{2}$ & 1.625 & 1.475 & 0.850 \\
$A_{3}$ & 0.900 & 0.850 & 1.275 \\
$A_{4}$ & 0.950 & 1.425 & 0.100 \\
$A_{5}$ & 1.100 & 0.925 & 0.850 \\
\hline Total & 5.425 & 5.250 & 3.425 \\
\hline
\end{tabular}

TABLE 2

\begin{tabular}{lllllllllllll}
\hline \multicolumn{9}{c}{$C_{1}$} & \multicolumn{3}{c}{$C_{2}$} & \multicolumn{3}{c}{$C_{3}$} \\
\hline$A_{1}$ & 0.448 & 0.561 & 0.161 & 0.225 & 0.453 & 0.554 & 0.209 & 0.274 & 0.347 & 0.448 & 0.439 & 0.532 \\
$A_{2}$ & 0.664 & 0.739 & 0.139 & 0.229 & 0.387 & 0.451 & 0.125 & 0.227 & 0.613 & 0.682 & 0.225 & 0.294 \\
$A_{3}$ & 0.459 & 0.531 & 0.125 & 0.176 & 0.748 & 0.853 & 0.000 & 0.130 & 0.370 & 0.435 & 0.209 & 0.310 \\
$A_{4}$ & 0.284 & 0.380 & 0.321 & 0.417 & 0.613 & 0.683 & 0.161 & 0.213 & 0.591 & 0.411 & 0.321 & 0.401 \\
$A_{5}$ & 0.858 & 1.000 & 0.222 & 0.321 & 0.212 & 0.312 & 0.321 & 0.374 & 0.588 & 0.674 & 0.200 & 0.255 \\
\hline
\end{tabular}

decision makers usually tend to avoid risk and pursue profit. The results are as follows.

(1) Calculating by the Hamming distance, the results are

$$
I_{1}=\left|\begin{array}{cccccc} 
& A_{1} & A_{2} & A_{3} & A_{4} & A_{5} \\
A_{1} & 0.000 & -1.666 & -2.077 & -1.091 & -1.848 \\
A_{2} & 0.268 & 0.000 & -0.835 & -0.346 & -0.810 \\
A_{3} & 0.543 & -1.214 & 0.000 & 0.344 & -1.499 \\
A_{4} & -0.952 & -2.056 & -2.398 & 0.000 & -2.192 \\
A_{5} & -0.478 & -0.836 & -1.147 & -0.790 & 0.000
\end{array}\right| .
$$

(2) Calculating by the Euclidean distance, the results are

$$
I_{2}=\left|\begin{array}{cccccc} 
& A_{1} & A_{2} & A_{3} & A_{4} & A_{5} \\
A_{1} & 0.000 & -1.865 & -2.149 & -1.062 & -1.818 \\
A_{2} & 0.544 & 0.000 & -0.803 & -0.247 & -0.860 \\
A_{3} & 0.568 & -1.057 & 0.000 & 0.427 & -1.405 \\
A_{4} & -0.932 & -1.996 & -2.527 & 0.000 & -2.153 \\
A_{5} & -0.399 & -0.799 & -1.107 & -0.711 & 0.000
\end{array}\right| .
$$

Step 7. According to expression (20), the overall evaluation value of each alternative can be worked out, and the results are as follows:

$$
\xi\left(A_{i}\right)=\left|\begin{array}{cccccc} 
& A_{1} & A_{2} & A_{3} & A_{4} & A_{5} \\
\text { on condition that Hamming distance } & 0.156 & 1 & 0.983 & 0 & 0.740 \\
\text { on condition that Euclidean distance } & 0.114 & 1 & 0.984 & 0 & 0.736
\end{array}\right| .
$$

Step 8. The values of function $\xi\left(A_{i}\right)$ should be ranked by ascending order after Step 7.

No matter what kinds of distance formulas were adapted in this process, such as the Hamming distance formula or the Euclidean distance formula, the final results of the sorting are consistent. And it is $A_{2}>A_{3}>A_{5}>A_{1}>A_{4}$. Therefore, $A_{2}$ is better than other alternatives; that is to say that when the airfield constructs an airport terminals in the surrounding cities, the second city will be the best choice. However, the final results of the sorting can also be used to judge the rationality of the position of the existing airport terminal. For example, assume that city $A_{3}$ and city $A_{1}$ already have airport terminals. In this case, if another airport terminal needs to be constructed, city $A_{5}$ should also be taken into consideration.

\section{Conclusion}

A method of multiple-attribute group decision making based on TODIM is proposed to evaluate the information of the IIFSs. The differences between this paper and other studies that discuss the TODIM method of group decision making in the case of unknown weights $[29,30,43,44,47]$ are made clear. The entropy evaluation method is applied to determine attribute weights and expert weights. The attribute value is expressed as the IIFSs, as distinct from previous expressions, such as the two-dimension linguistic variable and the triangle fuzzy value $[11,18,45,47]$.

First, we show that expert weights can be obtained using the original expert matrices. Second, we show how the matrices of IIFSs including different expert opinions can be 
TABLE 3

\begin{tabular}{lccc}
\hline$h_{i j}$ & $C_{1}$ & $C_{2}$ & $C_{3}$ \\
\hline$A_{1}$ & 0.778 & 0.812 & 0.912 \\
$A_{2}$ & 0.732 & 0.760 & 0.798 \\
$A_{3}$ & 0.751 & 0.622 & 0.812 \\
$A_{4}$ & 0.842 & 0.753 & 0.880 \\
$A_{5}$ & 0.651 & 0.796 & 0.783 \\
\hline Total & 3.754 & 3.743 & 4.185 \\
\hline
\end{tabular}

integrated. Then, we discuss how the attribute weights can be worked out on top of the aggregated expert matrix. Finally, using the Hamming distance and the Euclidean distance of the IIFSs, we accomplish the transformation of the matrix. The traditional TODIM method is improved so that it can be used to handle the IIFS information, allowing for a general ranking of the alternatives. Finally, a case concerning the site selection of airport terminals is described to show that the steps of the above method are operable and easy.

However, according to the Hamming distance and the Euclidean distance of the IIFSs, the transformation of the matrix is simple, and there must be a more accurate mapping function that can be used to express the relationship. Another deficiency of this paper is the simplicity of the method used to determine weights. Some studies have proposed other methods to solve the unknown weights problems, which may be applied to the extended TODIM method for group decision making with the IIFSs.

\section{Conflict of Interests}

The authors declare that there is no conflict of interests regarding the publication of this paper.

\section{Acknowledgments}

The authors also would like to express sincere appreciation to the anonymous reviewers and Editors for their very helpful comments that improved the paper. This paper is supported by the National Social Science Fund of China (no. 12BJY112) and the Fundamental Research Funds for the Central Universities of China (no. ZXH2010B002).

\section{References}

[1] L. A. Zadeh, "Fuzzy sets," Information and Computation, vol. 8, no. 3, pp. 338-353, 1965.

[2] K.-T. Atanassov, "Intuitionistic fuzzy sets," Fuzzy Sets and Systems, vol. 20, no. 1, pp. 87-96, 1986.

[3] D.-F. Li, "Closeness coefficient based nonlinear programming method for interval-valued intuitionistic fuzzy multiattribute decision making with incomplete preference information," Applied Soft Computing Journal, vol. 11, no. 4, pp. 3402-3418, 2011.

[4] K. Atanassov and G. Gargov, "Interval valued intuitionistic fuzzy sets," Fuzzy Sets and Systems, vol. 31, no. 3, pp. 343-349, 1989.
[5] K. T. Atanassov, "Operators over interval valued intuitionistic fuzzy sets," Fuzzy Sets and Systems, vol. 64, no. 2, pp. 159-174, 1994.

[6] H. Bustince and P. Burillo, "Correlation of interval-valued intuitionistic fuzzy sets," Fuzzy Sets and Systems, vol. 74, no. 2, pp. 237-244, 1995.

[7] T. K. Mondal and S. K. Samanta, “Topology of interval-valued intuitionistic fuzzy sets," Fuzzy Sets and Systems, vol. 119, no. 3, pp. 483-494, 2001.

[8] W.-L. Hung and J.-W. Wu, "Correlation of intuitionistic fuzzy sets by centroid method," Information Sciences, vol. 144, no. 1-4, pp. 219-225, 2002.

[9] G. Deschrijver and E. E. Kerre, "On the relationship between some extensions of fuzzy set theory," Fuzzy Sets and Systems, vol. 133, no. 2, pp. 227-235, 2003.

[10] Z.-S. Xu, "Methods for aggregating interval-valued intuitionistic fuzzy information and their application to decision making," Control and Decision, vol. 22, no. 2, pp. 215-219, 2007.

[11] J.-Q. Wang, R.-R. Nie, H.-Y. Zhang, and X.-H. Chen, "New operators on triangular intuitionistic fuzzy numbers and their applications in system fault analysis," Information Sciences, vol. 251, pp. 79-95, 2013.

[12] P.-D. Liu, Y.-C. Chu, Y.-W. Li, and Y.-B. Chen, "Some generalized neutrosophic number Hamacher aggregation operators and their application to Group Decision Making," International Journal of Fuzzy Systems, vol. 16, no. 2, pp. 242-255, 2014.

[13] J.-Q. Wang, P. Zhou, K.-J. Li, H.-Y. Zhang, and X.-H. Chen, "Multi-criteria decision-making method based on normal intuitionistic fuzzy-induced generalized aggregation operator," TOP, vol. 22, no. 3, pp. 1103-1122, 2014.

[14] B. Roy and B. Bertier, "La metode ELECTRE II," in Sixieme Conference Internationale de Rechearche Operationelle, Dublin, Ireland, 1972.

[15] P.-D. Liu and X. Zhang, "Research on the supplier selection of a supply chain based on entropy weight and improved ELECTREIII method," International Journal of Production Research, vol. 49, no. 3, pp. 637-646, 2011.

[16] S. Opricovic and G.-H. Tzeng, "Compromise solution by MCDM methods: a comparative analysis of VIKOR and TOPSIS," European Journal of Operational Research, vol. 156, no. 2, pp. 445-455, 2004.

[17] G.-W. Wei and Y. Wei, "Model of grey relational analysis for interval multiple attribute decision making with preference information on alternatives," Chinese Journal of Management Science, vol. 16, pp. 158-162, 2008.

[18] P. D. Liu and M. H. Wang, "An extended VIKOR method for multiple attribute group decision making based on generalized interval-valued trapezoidal fuzzy numbers," Scientific Research and Essays, vol. 6, no. 4, pp. 766-776, 2011.

[19] P. Liu, "Multi-attribute decision-making method research based On interval vague set and topsis method," Technological and Economic Development of Economy, vol. 15, no. 3, pp. 453-463, 2009.

[20] Z.-L. Yue, "An extended TOPSIS for determining weights of decision makers with interval numbers," Knowledge-Based Systems, vol. 24, no. 1, pp. 146-153, 2011.

[21] X. Zhao and G.-W. Wei, "Some intuitionistic fuzzy Einstein hybrid aggregation operators and their application to multiple attribute decision making," Knowledge-Based Systems, vol. 37, pp. 472-479, 2013. 
[22] P.-D. Liu and Y. Liu, "An approach to multiple attribute group decision making based on intuitionistic trapezoidal fuzzy power generalized aggregation operator," International Journal of Computational Intelligence Systems, vol. 7, no. 2, pp. 291-304, 2014.

[23] P.-D. Liu and Y.-M. Wang, "Multiple attribute decision-making method based on single-valued neutrosophic normalized weighted Bonferroni mean," Neural Computing and Applications, vol. 25, no. 7-8, pp. 2001-2010, 2014.

[24] P.-D. Liu and Y.-M. Wang, "Multiple attribute group decision making methods based on intuitionistic linguistic power generalized aggregation operators," Applied Soft Computing, vol. 17, pp. 90-104, 2014.

[25] J.-Q. Wang, J.-T. Wu, J. Wang, H.-Y. Zhang, and X.-H. Chen, "Multi-criteria decision-making methods based on the Hausdorff distance of hesitant fuzzy linguistic numbers," Soft Computing, 2015.

[26] W. Tao and G. Zhang, "Trusted interaction approach for dynamic service selection using multi-criteria decision making technique," Knowledge-Based Systems, vol. 32, pp. 116-122, 2012.

[27] W.-Y. Chiu, G.-H. Tzeng, and H.-L. Li, "A new hybrid MCDM model combining DANP with VIKOR to improve e-store business," Knowledge-Based Systems, vol. 37, pp. 48-61, 2013.

[28] D. G. Park, Y. C. Kwun, J. H. Park, and I. Y. Park, "Correlation coefficient of interval-valued intuitionistic fuzzy sets and its application to multiple attribute group decision making problems," Mathematical and Computer Modelling, vol. 50, no. 9-10, pp. 1279-1293, 2009.

[29] D.-F. Li, "Linear programming method for MADM with interval-valued intuitionistic fuzzy sets," Expert Systems with Applications, vol. 37, no. 8, pp. 5939-5945, 2010.

[30] Z.-S. Xu and X.-Q. Cai, "Nonlinear optimization models for multiple attribute group decision making with intuitionistic fuzzy information," International Journal of Intelligent Systems, vol. 25, no. 6, pp. 489-513, 2010.

[31] N. Bryson and A. Mobolurin, "An action learning evaluation procedure for multiple criteria decision making problems," European Journal of Operational Research, vol. 96, no. 2, pp. 379386, 1997.

[32] Z. Xu, "On method for uncertain multiple attribute decision making problems with uncertain multiplicative preference information on alternatives," Fuzzy Optimization and Decision Making, vol. 4, no. 2, pp. 131-139, 2005.

[33] Z.-X. Su, L. Wang, and G.-P. Xia, "Extended VIKOR method for dynamic multi-attribute decision making with interval numbers," Control and Decision, vol. 25, no. 6, pp. 836-840, 2010.

[34] J.-Q. Wang and H.-Y. Zhang, "Multicriteria decision-making approach based on atanassov's intuitionistic fuzzy sets with incomplete certain information on weights," IEEE Transactions on Fuzzy Systems, vol. 21, no. 3, pp. 510-515, 2013.

[35] J.-Q. Wang, R.-R. Nie, H.-Y. Zhang, and X.-H. Chen, "Intuitionistic fuzzy multi-criteria decision-making method based on evidential reasoning," Applied Soft Computing Journal, vol. 13, no. 4, pp. 1823-1831, 2013.

[36] H. Hu and Z.-S. Xu, "TOPSIS method for multiple attribute decision making with interval-valued intuitionistic fuzzy information," Fuzzy Systems and Mathematics, vol. 21, no. 5, pp. 108112, 2007.

[37] X.-W. Qi, C.-Y. Liang, Q.-W. Cao, and Y. Ding, "Automatic convergent approach in interval-valued intuitionistic fuzzy multiattribute group decision making," Systems Engineering and Electronics, vol. 33, no. 1, pp. 110-115, 2011.
[38] Y. Liu, J. Forrest, S.-F. Liu, H.-H. Zhao, and L.-R. Jian, “Dynamic multiple attribute grey incidence decision making mothed based on interval valued intuitionisitc fuzzy number," Control and Decision, vol. 28, no. 9, pp. 1303-1321, 2013.

[39] T.-Y. Chen, "Data construction process and qualiflex-based method for multiple-criteria group decision making with interval-valued intuitionistic fuzzy sets," International Journal of Information Technology and Decision Making, vol. 12, no. 3, pp. 425-467, 2013.

[40] L. F. A. M. Gomes and M. M. P. P. Lima, "TODIM: basics and application to multicriteria ranking of projects with environmental impacts," Foundations of Computing and Decision Sciences, vol. 16, no. 4, pp. 113-127, 1992.

[41] L. F. A. M. Gomes and M. M. P. P. Lima, "From modeling individual preferences to multicriteria ranking of discrete alternatives: a look at prospect theory and the additive difference model," Foundations of Computing and Decision Sciences, vol. 17, no. 3, pp. 171-184, 1992.

[42] D. Kahneman and A. Tversky, "Prospect theory: an analysis of decision under risk," Econometrica, vol. 47, no. 2, p. 263, 1979.

[43] L. F. A. M. Gomes and L. A. D. Rangel, "An application of the TODIM method to the multicriteria rental evaluation of residential properties," European Journal of Operational Research, vol. 193, no. 1, pp. 204-211, 2009.

[44] R. A. Krohling and T. T. M. De Souza, "Combining prospect theory and fuzzy numbers to multi-criteria decision making," Expert Systems with Applications, vol. 39, no. 13, pp. 11487-11493, 2012.

[45] Z.-P. Fan, X. Zhang, F.-D. Chen, and Y. Liu, "Extended TODIM method for hybrid multiple attribute decision making problems," Knowledge-Based Systems, vol. 42, pp. 40-48, 2013.

[46] X.-W. Qi, C.-Y. Liang, E.-Q. Zhang, and Y. Ding, "Approach to interval-valued intuitionistic fuzzy multiple attributes group decision making based on maximum entropy," System Engineering Theory and Practice, vol. 31, no. 10, pp. 1940-1948, 2011.

[47] P. Liu and F. Teng, "An extended TODIM method for multiple attribute group decision-making based on 2-dimension uncertain linguistic Variable," Complexity, 2014. 


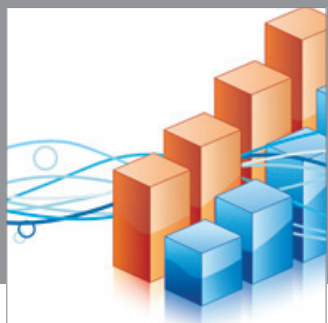

Advances in

Operations Research

mansans

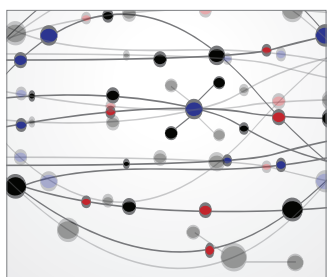

The Scientific World Journal
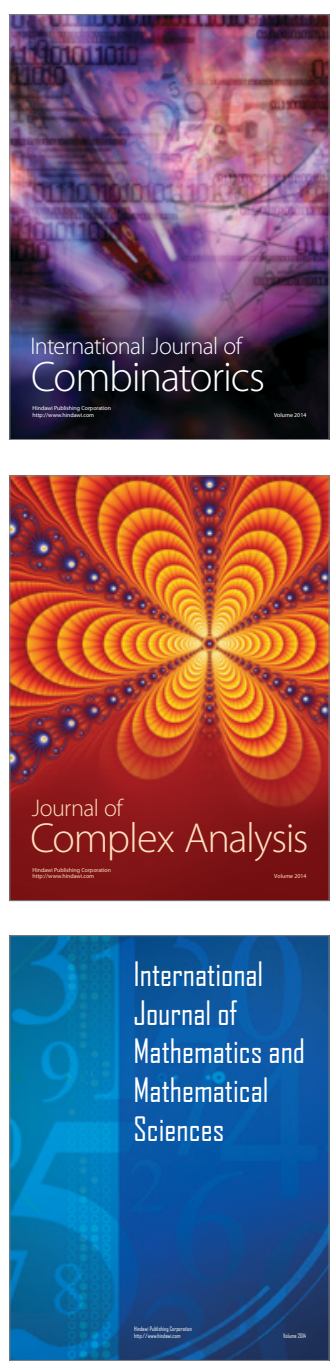
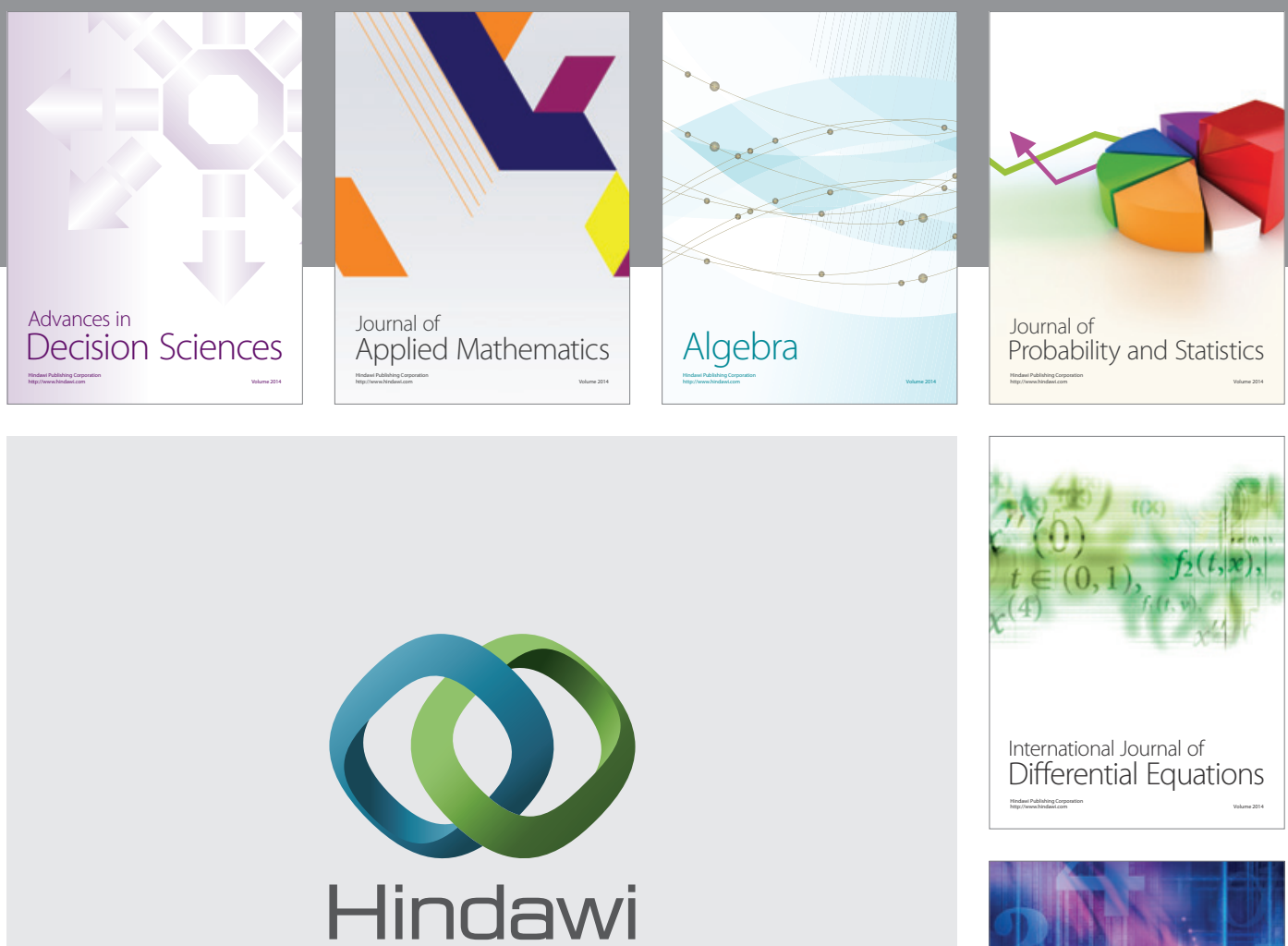

Submit your manuscripts at http://www.hindawi.com
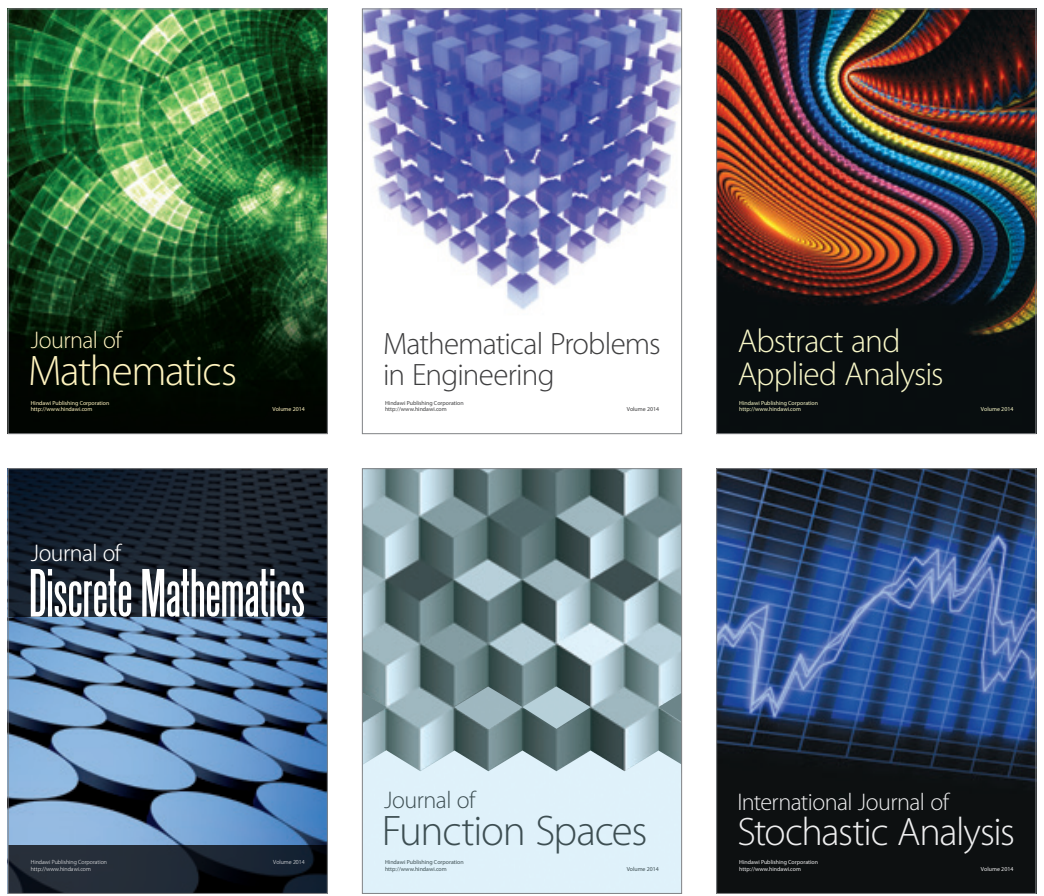

Journal of

Function Spaces

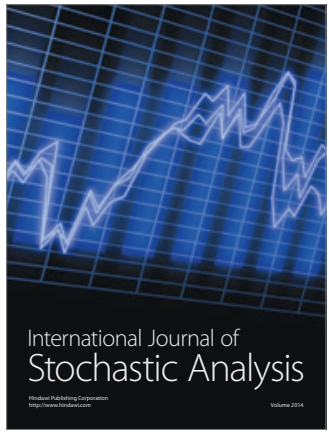

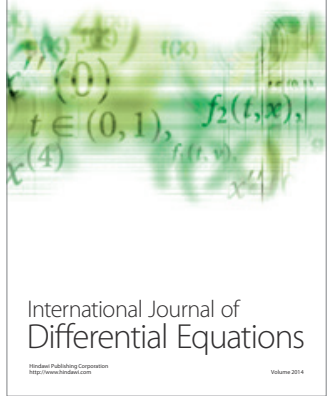
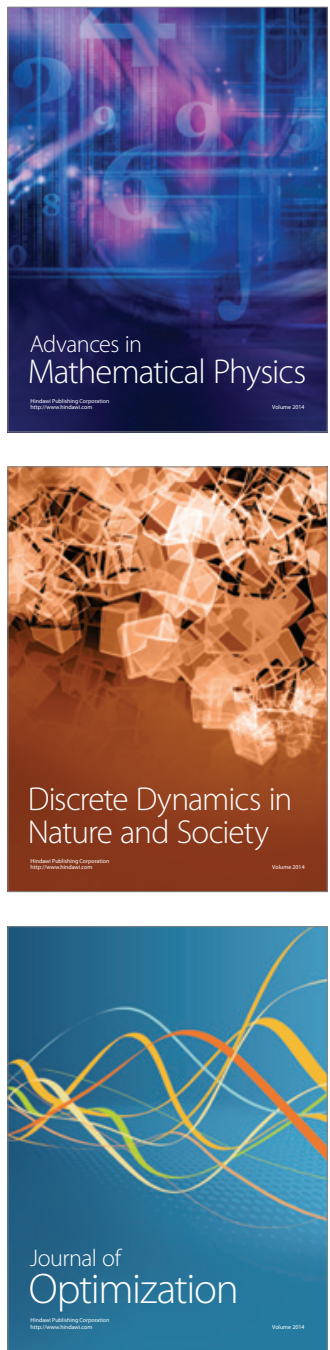